\title{
How to measure and report the capacity of electrochemical double layers, supercapacitors, and their electrode materials
}

\author{
Yuru Ge ${ }^{1} \cdot$ Xuan Xie $^{2} \cdot$ Jessica Roscher ${ }^{1} \cdot$ Rudolf Holze $^{1,3,4}$ (D) $\cdot$ Qunting Qu ${ }^{5}$ \\ Received: 25 May 2020 / Revised: 11 August 2020 / Accepted: 12 August 2020 / Published online: 27 August 2020 \\ (C) The Author(s) 2020
}

\begin{abstract}
Relevant fundamentals of the electrochemical double layer and supercapacitors utilizing the interfacial capacitance as well as superficial redox processes at the electrode/solution interface are briefly reviewed. Experimental methods for the determination of the capacity of electrochemical double layers, of charge storage electrode materials for supercapacitors, and of supercapacitors are discussed and compared. Intrinsic limitations and pitfalls are indicated; popular errors, misconceptions, and mistakes are evaluated. The suitability of available methods is discussed, and practical recommendations are provided.
\end{abstract}

Keywords Supercapacitor · Differential double layer capacity $\cdot$ Integral double layer capacity

\section{Introduction}

Capacitors as a means of storing electric energy without any transformation are standard for decades; supercapacitors as devices showing capacitances and thus storage capabilities bigger by orders of magnitude are a recent addition in electrical engineering. In the search for better materials and their combinations, standards of reporting have been less than perfect; demands for more uniform reporting are almost as old as the research in this field [1].

Whenever an ionically conducting phase (e.g., an electrolyte solution) and an electronically conducting phase (e.g., a metal or graphite) are brought into contact, an electrochemical

Dedicated to Fritz Scholz on the occasion of his 65th birthday in recognition of his numerous contributions to fundamental and applied electrochemistry and to scientific communication. And foremost to a friend.

Electronic supplementary material The online version of this article (https://doi.org/10.1007/s10008-020-04804-x) contains supplementary material, which is available to authorized users.

Rudolf Holze

Rudolf.holze@chemie.tu-chemnitz.de

1 Institut für Chemie, AG Elektrochemie, Technische Universität Chemnitz, D-09107 Chemnitz, Germany

2 Key Laboratory for Anisotropy and Texture of Materials (MoE), School of Materials Science and Engineering, Northeastern University, Shenyang 110819, China double layer is established. Its structure, its properties, and its behavior have fascinated electrochemists, surface scientists, biologists, tribologists, and scientists from other fields for many decades. Its capacitor-like behavior known since the work of Lippmann [2, 3], Perrin [4], Stern [5], Gouy [6-8], Chapman $[9,10]$, Helmholtz [11], and others has been frequently treated by experimentalists more like a nuisance causing a non-Faradaic charging current. Only those interested in fundamentals of electrochemistry have studied the structure and dynamics of the electrochemical interface thoroughly and without trying to get around its effects as in, e.g., polarography. For an early overview highlighting the work by Grahame [12], see [13], for more recent ideas [14].
3 Institute of Chemistry, Saint Petersburg State University, St. Petersburg 199034, Russia

4 State Key Laboratory of Materials-oriented Chemical Engineering, School of Energy Science and Engineering, Nanjing Tech University, Nanjing, Jiangsu Province 211816, China

5 College of Energy, Soochow Institute for Energy and Materials InnovationS, Soochow University, Suzhou 215006, Jiangsu, China 
Dynamics of the ion-conducting phase (the electrolyte solution) adjacent to this interface especially with respect to sudden changes of, e.g., current or electrode potentials/cell voltage have been inspected elsewhere [15]. Wetting in particular of materials for electrochemical double layer capacitors EDLCs has been examined with respect to the current understanding of the theoretical foundations [16].

Actual values of this electrochemical double layer capacity $^{1}$ in $\mu \mathrm{F} \mathrm{cm}$ (more specifically of geometric or of true or of electrochemically active surface area (see [17]) depend on numerous factors and parameters like identity of the metal or any other electronically conducting material, its crystallography, composition of the electrolyte solution, and electrolyte concentration $[18,19]$. A most frequently used value is $20 \mu \mathrm{F}$ $\mathrm{cm}^{-2}$ for a perfectly smooth metal surface in contact with a moderately concentrated electrolyte solution. This is very close to the value calculated in Eq. 1 with the Helmholtz model of a parallel-plate condenser assuming

$C=\frac{\varepsilon}{4 \cdot \pi \cdot d}$

with distance $d=300 \mathrm{pm}$ and permittivity $\varepsilon=6 \mathrm{~F} \cdot \mathrm{m}^{-1}$ yielding $C=18 \mu \mathrm{F} \mathrm{cm}^{-2}$. Values ranging from $C=15 \mu \mathrm{F} \mathrm{cm}^{-2}$ up to $C$ $=50 \mu \mathrm{F} \mathrm{cm}^{-2}$ have been discussed elsewhere [20]. Determination of relevant experimental numbers was and is still mostly based on cyclic voltammetry performed at various scan rates and electrochemical impedance measurements. Practically observed numbers are too small for any practical application in electrochemical energy conversion and storage. Capacitances observed with so-called electrolytic capacitors $[21,22]$ are much larger with respect to the geometric electrode surface, but this is based on artificially generated roughness resulting in a much larger true interfacial area. In addition the capacity depends on the properties of the interface with a thin layer of $\mathrm{Al}_{2} \mathrm{O}_{3}$ or other valve metal oxides like $\mathrm{Ta}_{2} \mathrm{O}_{5}$ acting as dielectric between the metal, the ionically conducting electrolyte, and the counterelectrode material. These devices are not considered here; they are commonly ignored when discussing supercapacitors.

True double layer capacities exploded into technologically relevant data with the reports and patents of Becker [23] and Rightmire [24] (for later details of this technological development, see [25]) on observations made with porous carbon electrodes. The large surface area of activated carbon pressed into porous pellets subsequently used as electrodes when

\footnotetext{
${ }^{1}$ Although the correct technical term is capacitance among electrochemists, the term capacity is frequently used, almost like a synonym. This confusion has been addressed elsewhere before [74]. Only recently in the debate about capacitive, pseudocapacitive, and non-pseudocapacitive behaviors of electrochemical interfaces in particular in supercapacitor electrodes attempts have been made to turn this rather harmless confusion and habit into a problem, apparently based on rather artificial arguments [75]. In this text, capacitance will be used.
}

brought into contact with aqueous electrolyte solutions made double layer capacitances of many Farads a technically feasible option. When two electrodes are inserted into a common electrolyte solution, the respective double layer capacitances $C_{\mathrm{DL} 1}$ and $C_{\mathrm{DL} 2}$ act as two capacitors connected in series. Although according to eq. 2 the measured capacity $C$ of the capacitor is only

$\frac{1}{C}=\frac{1}{C_{\mathrm{DL} 1}}+\frac{1}{C_{\mathrm{DL} 2}}$

but the numbers are still impressive. Surface-confined redox transformations of many compounds insoluble in the employed electrolyte solution (e.g., $\mathrm{RuO}_{2}$ or $\mathrm{MnO}_{2}$ in aqueous electrolyte solutions) show a current response in CVs fairly similar, capacitor-like (for a typical example, see [26]). Because the underlying process is not simply charging of an electrochemical interface and local separation of charged species without any associated Faradaic reaction, this behavior has been called pseudocapacitive [20]; for a more recent discussion of the term and its application, see [27]. Experimental details and observations will be discussed below. The confusion between Faradaic, capacitive, and pseudocapacitive behavior/current response of electrode materials has been addressed also by Ragoisha and Aniskevich [28] by repeating previous arguments already collected in [27] without adding new arguments or considerations.

Measurements of these values can be performed with various methods: galvanostatic charge/discharge (in electroanalytical chemistry this procedure is also known as chronopotentiometry [29-32]), potentiostatic ${ }^{2}$ charge/ discharge (again in electroanalytical chemistry this procedure is known as chronoamperometry, but frequently and sometimes slightly confusingly cyclic voltammetry is listed also under this header), and impedance measurements.

The highly porous structure of the electrodes (both the carbon ones for EDLC supercapacitors and the redox-active materials for redox-supercapacitors) already suggests serious limitations of these methods with respect to the validity of the obtained results. Penetration of the electronic and even more importantly of the electrolytic (ionic) current into the pores and the highly structured electronically conducting solid depends on the rate of potential change, the current, or the frequency of the electrode potential or current modulation applied in impedance measurements. At zero rate of change, current or zero frequency equilibrium will be established across the electrode/solution interface and inside the porous body independent of how porous it might be. In reality only this will be the theoretical limit. Thus, at least inspection of empirical relationships between rate of change (i.e., scan rate in $\mathrm{CV}$, current in GCD, and frequency in impedance

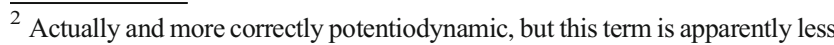
popular.
} 
measurements) and actually observed capacitances of electrode double layer or of a capacitor is needed. This has been done for potentiostatic measurements of charges involved in redox transformations of $\mathrm{RuO}_{2}$ electrodes as reported by Ardizzone et al. [33]. Initial criticism related in particular to an assumed lack of sound justification [34] has been critically examined [35]; the suitability of the approach appears to be out of question. Another separation is frequently attempted: the distinction between capacitive and Faradaic contributions to charge storage and their formal separation. This subject will be addressed below. Always a decrease of measured electrode double layer as well as (super) capacitor redox capacitance as a function of the rate of electrode potential change or charge/ discharge current is observed; it is mostly reported as capacity retention (in \%) with respect to the highest number found at whatever experimental conditions applied in a given study.

Closely related to the mode of charge storage (both EDLC and redox storage) and the frequently highly developed porosity is dielectric absorption [36, 37] (also called dielectric relaxation or soakage [38]). Effects of this phenomenon are easily observed when the voltage of a capacitor (both a conventional and a supercapacitor) returns to a small value $(>0 \mathrm{~V})$ after discharge by short-circuit (typically 0.01 to $10 \%$ of the value before short-circuiting). With a supercapacitor, this is due to charge stored inside the porous material not fully participating in the discharge mostly because of transport limitations. It might also indicate charge trapping. In conventional capacitors employing non-porous electrodes and various solid dielectrics, further mechanisms may be effective. This phenomenon becomes more obvious when a charged device is stored for longer periods of time enabling charges to distribute evenly within the electrode material including locations farther away from the current collector. Given the relatively high selfdischarge of supercapacitors, it is not surprising that this phenomenon has hardly been addressed in published reports. To ensure reproducibility, it is recommended to short-circuit a supercapacitor for about $15 \mathrm{~min}$ before testing [36].

Given the ongoing chase for the highest electrode and cell capacitances, correct and comparable measurement and reporting seem to be highly relevant. Certainly reported numbers may be correct, but because of different experimental settings and missing points of reference and standards, results are hardly comparable. Already the omission of information about inclusion of binder, added conducting carbon, and current collector (or their exclusion) might result in gross misinterpretations of data specific with respect to mass or volume. The preference for gravimetric data further reduces practical importance of reported data because quite obviously volumetric data are technologically more relevant. The need is further reinforced by the development of asymmetric supercapacitors or more generally devices, wherein a supercapacitor and a battery electrode are combined. Proper matching of the overall storage capability will help to utilize materials as good as possible. This obvious fact has been highlighted [39] although the assumption that such combination (the term hybridization appears to be a bit misleading) might help to increase the energy density of supercapacitors appears to be somewhat confusing.

In a representative case study, excessive claims of overwhelming performance of a complete cell were reduced to true size by a careful examination [40]. Although frequently data are reported with respect to current density (per volume, per weight, or per apparent surface area) or with stating C-rate, the reader can sometimes only guess the point of reference. The use of C-rates has recently been reexamined by Jorne [41]. Data for the same material examined with a thin or a thick electrode and with the current collector in different locations will provide most likely different results when measured at the same C-rate with the former thin electrodes always performing better. Stating C-flux (current with respect to electrode area) instead of C-rate (current with respect to mass) has been suggested as a remedy. These considerations are directly connected to the thickness of the electrode. As examined elsewhere [42], specific data obtained with extremely thin electrodes are always better than with thick electrodes although the former ones may be practically irrelevant.

Some considerations for measurement and reporting have been reported before [43, 44]; surprisingly these arguments were basically repeated later [45], sometimes even without mentioning the more extensive earlier work [46]. These reports lack clear definition and a complete overview of available and currently employed methods and procedures. A book whose title seems to answer all questions asked here the present authors failed to comprehend [47]. The same applies to a report claiming to provide a new approach to improved interpretation of capacitance measurements [48].

The following measurement methods and considerations are presented in an attempt to suggest some guidelines. The overwhelming and hardly adequately addressed question for materials stability and other materials-related questions are not considered in the present context.

\section{Methods}

\section{Double layer and electrode capacitance}

The capacitance of the electrochemical double layer $C_{\mathrm{DL}}$ can be considered either in differential form $[49,50]$ :

$C_{\text {diff }}=\frac{\partial Q}{\partial E}$

or in integral form: 
$C_{\mathrm{int}}=\frac{\Delta Q}{\Delta E}$ or $C_{\mathrm{int}}=\frac{q}{E-E_{p z c}}$

with the electrode potential of zero charge $E_{\mathrm{pzc}}$ and $q=\Delta Q$. They are related to each other according to:

$C_{\mathrm{diff}}=\left(E-E_{\mathrm{pcz}}\right) \frac{\partial C_{\mathrm{int}}}{\partial E}+C_{\mathrm{int}}$

Both values can be determined experimentally [30, 51-55]; care should be exercised in not confusing them (see below for an example). The former value is mostly discussed in experimental electrochemistry (for details, see, e.g., [29, 54]). Experimental methods reviewed briefly in the next section are based on controlled change of electrode potential, on controlled flow of current across the interface (the current flow may be associated with a Faradaic reaction and/or with accumulation/dispersion of ions), or on the response to a modulation of electrode potential or flowing current by a timedependent signal in impedance measurements.

All approaches based on measuring the current response of an electrode under study to a change of electrode potential are suitable only when the electrode/electrolyte solution interface shows non-Faradaic behavior within a suitably wide range of electrode potentials (commonly called double layer region). A typical example (although of no technical-practical relevance) is shown below with a $\mathrm{CV}$ of a polycrystalline gold electrode (Fig. 1) with this double layer range at $0.1<E_{\mathrm{RHE}}<0.8 \mathrm{~V}$.

Plotting the current registered in this range of electrode potentials versus scan rate yields a graph in Fig. 2 with the slope equal to $C_{\text {diff. }}$

A plot in the range of electrode potentials around $E_{\mathrm{RHE}}=1$. $5 \mathrm{~V}$ yields a straight line, too, but with a much larger value of slope and accordingly apparent capacitance $C_{\text {diff }}$ quite

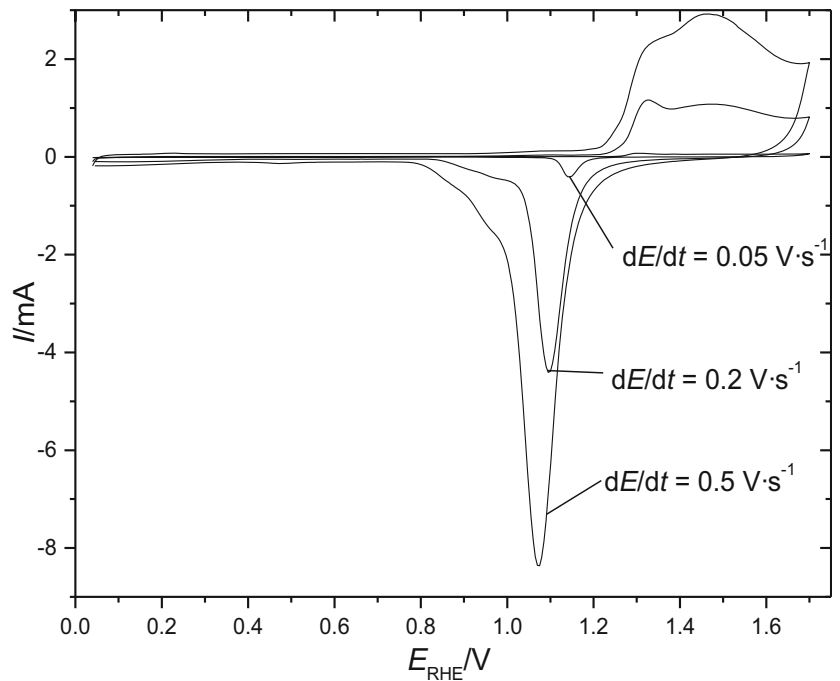

Fig. 1 Cyclic voltammograms of a polycrystalline gold electrode in contact with an aqueous electrolyte solution of $1 \mathrm{M} \mathrm{HClO}_{4}$, nitrogen purged, scan rates as indicated impossibly due to double layer charging. Various features of the shape of the $\mathrm{CV}$ in this range of electrode potential and the dependency of current everywhere in this range on the potential scan rate suggest designation of the behavior as pseudocapacitive. More on this subject of intense debate is in [27]. A similar behavior of a $\mathrm{RuO}_{2}$-covered electrode has been reported by Burke and Murphy [56]; its interpretation with respect to surface area of the electrode is somewhat clouded by unclear terminology. More recently and with optimized electrode architectures, it has been observed again [57]; there are many more observations reported.

The dependency of the current flowing across the electrochemical interface on the scan rate can be written as

$$
I=C_{\text {diff }} \cdot \mathrm{d} E / \mathrm{d} t
$$$$
\text { or using } v=\mathrm{d} E / \mathrm{d} t
$$

$I=C_{\text {diff }} v$

for an electrode showing no Faradaic reaction, i.e., in the double layer region. Quite obviously this can be taken as a specific case of a general power law relationship

$I=\mathrm{a} \cdot v^{\mathrm{b}}$

with the exponent $b=1$. Because the exponent $b=0.5$ suggested similarity of the equation to the well-known relationship of peak current on scan rate as provided in the RandlesŠevčik equation, authors have frequently assumed that even a current peak showing such a dependency with $b=1$ (or close to 1) must be due to a capacitive process; for a nonrepresentative selection of examples, see [58-64]. Unfortunately the authors did not provide a description of their understanding of a capacitive process; obviously they assumed that the power law description sufficed as an explanation. The idea that every device showing a current response to a changing potential (voltage) like a capacitor must be

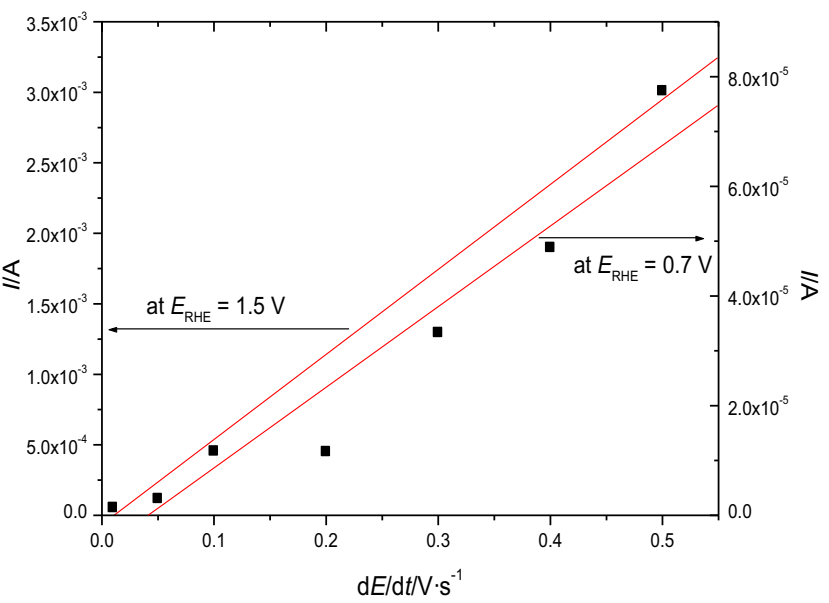

Fig. 2 Current response vs. scan rate of a polycrystalline gold electrode in contact with an aqueous electrolyte solution of $1 \mathrm{M} \mathrm{HClO}_{4}$ at different electrode potentials 
capacitive or at least pseudocapacitive [64] seems to be less than conclusive. As already illustrated above, the observed current with its particular magnitude - and at any electrode potential in the range of the formation of the gold hydroxide/ oxide formation, the same plot and the same slope will be obtained - is not at all due to a capacitive process, but is due to a surface-confined Faradaic process. Based on the two current vs. scan rate dependencies (i.e., the two exponents in said power law), authors have divided the current at basically every electrode potential in a CV into a capacitive and a Faradaic part $[58,59]$ with frequently rather disturbing results. For nanoparticle $\mathrm{TiO}_{2}$ depending on particle size, more than $50 \%$ of the charge storage was deemed to be capacitive, and because it was assigned to surface-near electrode reactions, it was called pseudocapacitive. This pseudocapacitive fraction grew to $84 \%$ in case of nano-particular MoC embedded in a $3 \mathrm{D}$ network of nitrogen-doped carbon [65]. Unfortunately the displayed results of the impedance measurements are highly selective and incomplete; details on, e.g., the value of $C_{\text {diff }}$ might have helped in understanding the reasons of the remarkable power retention. For sodium ion storage materials, the percentage reached 95\% [66], 82.8\% [67], or 90.3\% [68]. The criteria for calling a material pseudocapacitive defined and discussed elsewhere [27] based on the fundamental considerations specified earlier [20] apparently were hardly taken into account. Related materials like titanium niobates showing numerous pronounced current peaks [69] have met the same treatment. Because of the common perception that only a capacitor can provide large currents, good rate performance of an electrode (i.e., high current capability even at large scan rates or small electrode overpotentials at large currents), which indeed is frequently observed with electrode materials both for batteries and supercapacitors, has been assigned to capacitive or pseudocapacitive processes. A much simpler explanation is obviously overlooked as being either too simple or not being fancy enough: Such material shows a particularly welldesigned electrode morphology with a large fraction of the active material close to the contact interface with the electrolyte solution thus accessible for the electrode reaction without significant hindrance in particular by solid-state diffusion. This separation briefly discussed above has been demonstrated elsewhere as being physically meaningless [70].

By integration of the CV-trace between two electrode potential values set apart by $\Delta E$, the value of $C_{\text {diff }}$ is also available; this approach is particularly recommended when the current response is not a flat line as expected for a capacitive behavior of the electrode. Applicability of this approach in particular with low scan rates was confirmed elsewhere [71]; data from CVs were found to be close to true equilibrium double layer capacity values (i.e., not affected by diffusion effects) as compared with the data from impedance measurements. These considerations are equally valid for electrode materials showing a pseudocapacitive behavior [27, 72-75].
The storage capability of an electrode (whether it is due to the interfacial double layer capacitance of materials subsequently employed in EDLC capacitors or the redox reactions providing a pseudocapacitive or non-pseudocapacitive response) can also be measured using galvanostatic charge/ discharge measurements. From duration of discharge/charge, set current, and change of electrode potential, the capacitance is calculated. The shape of the curve may suggest the type of behavior with a perfectly straight line indicating capacitive or pseudocapacitive behavior, whereas any significant deviation, in particular steps and plateaus, signal redox processes and thus no pseudocapacitive behavior.

Finally impedance measurements can be applied to electrodes [76-78]. They are an almost standard feature in scientific reports on supercapacitor electrode materials. In the latter case, most unfortunately the application of this method goes hardly beyond a display of obtained data in Nyquist plots and some mostly diffuse description of the observed traces. Assignment of the various segments (lines, semicircles, etc.) to electrochemical phenomena and processes is mostly limited to trivial statements. An introductory overview on impedance measurements applied to electrode materials and supercapacitor devices has been reported [79]. Pitfalls and inherent limitations quite naturally suggesting the use of further methods for a critically cross-check of impedance results are highlighted as has been done before [80, 81]. Frequently it is even not stated whether an electrode or a cell impedance has been measured or discussed [82]. Evaluation of data, even reporting of obtained numbers, is missing. For a typical example, see [83]. When evaluation by fitting of an equivalent circuit is attempted, comparisons of measured and fitted data frequently are not displayed, neither are the applied equivalent circuits or transfer functions and a complete list of all parameters describing them are given. A purported limitation of impedance measurements has been reported by Wang and Pilon [84]. The authors state that capacitances obtained from impedance measurements at low frequencies have been found to be lower consistently than values obtained with other methods. Already the starting condition "measured at low frequencies" might have raised concerns: double layer capacities (i.e., $C_{\text {diff }}$ ) are obtained from impedance measurements always by considering the whole frequency range wide enough to include contributions in particular of the examined details. In a study of double layer and kinetic parameters (for a typical example, see [17]), the upper frequency limit will mostly be given be cell geometry and experimental setup, the lower limit by the onset of diffusion contributions, and the stability of the studied object or time constraints. Determination of $C_{\text {diff }}$ in a limited frequency range and in particular at low frequencies is thus scientifically unwarranted. These concerns have been examined more closely by Roling and Drüschler [85]. These authors stated perfect agreement between values of $C_{\text {diff }}$ properly derived from 
impedance measurements and values derived from a PoissonBoltzmann-type model, whereas in the Poisson-Nernst-Planck model applied by Wang and Pilon, the integral double layer capacitance obtained was - as stated above - not equivalent

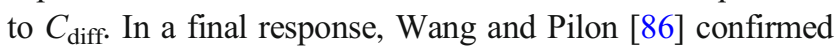
the confusion suggested as the possible explanation of the inconsistency insinuated earlier; they stressed once again the danger of confusing integral and differential double layer capacitance. The need to consider the whole frequency range was not even addressed.

More complicated approaches, in particular equivalent circuits, have been reported (for an example, see [87]) without visible benefit. Practical aspects of capacitance measurements have been critically reviewed elsewhere [43].

\section{Capacitor and supercapacitor capacitance}

Various experimental approaches are available in the lab; for commercial and field use in electrical engineering, professional instruments are available in addition.

Similar to the methods applied for double layer capacitance, measurements of the current flowing in response to a changing applied voltage (potentiostatic measurement) or the change of cell voltage as a function of applied current (galvanostatic measurement) are used. A further method also employing electrode potential control has been suggested [32], but it seems to enjoy limited application only. In this method, an electrode potential step is applied, and the current response is recorded. From a plot of $\ln I$ as a function of time the Ohmic resistance of the capacitor (electric series resistance ESR) and the capacitance can be derived. Experimental conditions as well as results and their interpretation in [32] are rather confused; in any case, this method does not provide the adjustable parameter "rate of change of state of charge" by different charging currents or scan rates identified as an important experimental option below. Extended application of DC pulses, etc. for the determination of supercapacitor performance beyond measuring the capacitance has been discussed elsewhere [88]. In addition cell impedance measurements are employed [82]. The effect of state of charge and temperature on the cell impedance has been examined [89].

The procedure to determine capacitance $C$ and other relevant device parameters is described in the European Standard EN 62391-1 [90]. Basically the time $\Delta t$ passed during a constant current discharge between an upper $U_{\mathrm{h}}$ and a lower voltage $\mathrm{U}_{\mathrm{l}}\left(U_{\mathrm{h}}=0.8 U_{\mathrm{r}}\right.$ and $U_{\mathrm{l}}=0.4 U_{\mathrm{r}}$ with the rated voltage $U_{\mathrm{r}}$ of the device) is measured. The discharge current is determined as $U_{\mathrm{r}} \cdot C / 3600$ assuming a discharge within 1 hour (3600 s). The capacitance is calculated from the recorded time $\Delta t$ according to

$C=\frac{I \Delta t}{\Delta U}$
In this recommendation, the internal resistance of a device is taken from the discharge current and the immediate voltage drop observed when switching on the discharge current. The obtained value of the internal resistance is sometimes called DC impedance (see, e.g., [36]).

A similar procedure with a charging instead of a discharging current applied is described in [36]. The distinction between the internal resistance or DC impedance (being more relevant for practical purposes) and the ESR or AC impedance measured by impedance or LCR bridge (at $1 \mathrm{kHz}$ ) measurements is stressed. The internal resistance has been reported to be 1.1 to 1.5 times the ESR [36]. In this procedure, the current going into charge storage (i.e., dielectric absorption in a broader sense) and leakage current are difficult to separate. They can be detected after long charging times $(100 \mathrm{~h}$ or more) as the residual current flowing under constant voltage charging using a shunt resistor [36]. A commercial device for the measurement of ESR is depicted in Fig. S3. Typical results obtained with this device operating at an AC frequency of $100 \mathrm{kHz}$ are collected in the Supplementary Information.

Measurements of cell AC impedances are commonly performed to get both capacitance and ESR values. Various modes of operation, i.e., at constant voltage and at constant current, are possible. A combination of both has been suggested by a manufacturer [91] wherein the applied AC current is adapted during an experiment to keep the amplitude of the registered $\mathrm{AC}$ response of the cell at a roughly constant value when changing the $\mathrm{AC}$ frequency.

Practical devices most frequently simplify the formal procedure described above by, e.g., using a fixed current not exactly set according to the data of the capacitor. In professional measuring devices, various principles are applied. In the device depicted in Fig. S1 [92], a constant voltage feeds a current limited by a high-precision resistor into the capacitor under investigation. The obtained charging curve is nonlinear, but any error caused by an imperfect constant current source is thus avoided. Using comparator circuits, a lower and an upper voltage passed during charging are registered. When passing the lower one, a logic gate is opened, and pulses from a highly stable generator source are fed into a counter. When the upper voltage has been reached, the gate is closed; from the number of counted pulses and the circuit details, the capacity can be displayed directly. In more simple devices, a constant current (with their inherent problems of precision) is applied; the rate of voltage increase is determined and again yields the capacitance.

Measurement of the AC current caused by application of an AC voltage of a fixed frequency $f$ is possible only with nonpolarized capacitors (i.e., definitely not with SCs) and within a range of capacity values wherein the impedance of the capacitor according to $Z=1 /(2 \pi f C)$ with frequency $f$ of the 
applied AC voltage is significantly larger than the resistance of all other Ohmic components (wires, contacts, etc.) in the used electric circuit (for a typical device, see Fig. S2). As stated, this approach is obviously not suitable for SCs. The same applies at first glance to true impedance measurements, i.e., AC measurements over a wide range of frequencies. As shown before, a number taken just at one frequency (as in the preceding simple approach) is most likely meaningless; measurements at various frequencies are no attractive option for engineering application. They will provide the true value of the capacitance of a SC only after modeling with a sufficiently elaborate equivalent circuit as reported, e.g., in [93] is employed.

Specific effects of experimental details like mechanical pressure applied to an electrode pack have been studied [94].

\section{Terminology}

The capacitance is the characteristic property of a capacitor giving its capability to store electric charge with respect to the difference in electric potential between the plates of the capacitor; it is given in $\mathrm{F}$, i.e., in $\mathrm{As} \cdot \mathrm{V}^{-1}$. Frequently the more general term capacity naming a general storage capability is used somewhat imprecisely as a synonym. The capability of an electrode material to store electric charge by undergoing a redox reaction is frequently called capacity, but apparently there is no generally accepted or even specifically designated term. This capability is measured in terms of charge, i.e., $\mathrm{C}$ or As. Any number is useful only when it refers to a specific redox reaction: $1 \mathrm{~mol}$ of $\mathrm{Li}$ converted into $1 \mathrm{~mol}$ of $\mathrm{Li}^{+}$-ions releases $1 \mathrm{~mol}$ of electrons with a total charge of 96494 As. Such number is useful when discussing battery electrodes where in the ideal case (assumed when stating the theoretical number) the complete active mass is converted. Although the fields of batteries and supercapacitors are already approaching for some time and with respect to many materials have merged already, this concept of storage capability hardly is useful when a battery electrode material is used and appraised as a supercapacitor electrode. By definition electrode reactions at supercapacitor electrodes are superficial reactions; once they proceed into the volume of an electrode, their real rate goes down, and so goes the current capability of this electrode. Accordingly any theoretical number for a storage material in a supercapacitor electrode is of rather dubious value. Even in extremely thin electrodes, it is unrealistic, actually incorrect almost by definition. In an actual measurement of this storage capability depending on which method is used, the state of oxidation of the material is changed from an initial value to a final value (both in $\mathrm{CV}$ and in GCD). The complete charge transferred in this process is divided by the potential difference yielding a result in the units $\mathrm{As} \cdot \mathrm{V}^{-1}$ — which is in terms of units exactly the same as with capacitance. This line of reasoning applies also to the evaluation of $\mathrm{CVs}$ with a flat current response (the frequently invoked rectangular shape of a CV which mutates into all kinds of "almost" shapes in the majority of publications; for a collection of samples, see [28]) wherein the current at a selected potential is recorded and transformed according to current/scan rate again yielding a result with the units $\mathrm{As} \cdot \mathrm{V}^{-1}$ which can be a true capacitance or a pseudocapacitance. The first and second approaches may be called integral one, the third differential (not to be confused with integral and differential double layer capacitance). Obviously the third approach may only be used with flat current responses; otherwise, gross errors will result. With both $\mathrm{CV}$ and GCD, the potential limits can have substantial effects on the obtained results. At first glance, division of the measured charge by the potential difference should cancel out any differences. In reality this may be an unjustified assumption. Frequently close to the potential limits side reactions like oxygen evolution (easily identified in CVs with rising currents) set in which are unwanted in most cases and will result in artificially enhanced results.

\section{Experimental}

\section{Electrode measurements}

$\mathrm{MnO}_{2}$ electrodes were prepared potentiostatically according to $\mathrm{Hu}$ and Tsou [95] with a platinum sheet counter and a saturated calomel reference $\left(E_{\mathrm{SCE}}\right)$ electrode in a threecompartment cell in a stirred solution. Working electrodes were prepared from stainless steel mesh (SS 1.4401, mesh 181 with $0.09 \mathrm{~mm}$ width and $0.05 \mathrm{~mm}$ thickness; F. Carl Schröter, Hamburg, Germany). The electrolyte solution for deposition contained $0.25 \mathrm{M} \mathrm{MnSO}_{4}$ (VEB Jenapharm Laborchemie Apolda) dissolved in deionized ultrapure 18 $\mathrm{M} \Omega$ water (Seralpur Pro $90 \mathrm{C}$ ). The $\mathrm{pH}$ was adjusted to 6.4. A representative thin electrode with low $\mathrm{MnO}_{2}$-loading and a thick electrode with larger loading were prepared. Deposition charges were measured with a coulombmeter model 630 (The Electrosynthesis, E. Amherst). Amounts of deposited $\mathrm{MnO}_{2}$ expected from coulomb-metrically and gravimetrically determined-are compared in Table 1.

Table 1 Expected and determined masses of electrochemically deposited $\mathrm{MnO}_{2}$

\begin{tabular}{lll}
\hline Deposition charge $Q / \mathrm{C}$ & $\begin{array}{l}\text { Expected } \\
\text { mass } m / \mathrm{mg}\end{array}$ & $\begin{array}{l}\text { Gravimetrically } \\
\text { determined mass } m / \mathrm{mg}\end{array}$ \\
\hline 0.3 & 0.13515 & 0.65 \\
3 & 1.3515 & 2.2 \\
\hline
\end{tabular}


Table 2 Corresponding scan rates and galvanostatic charge/discharge currents

\begin{tabular}{lll}
\hline Capacitance/F & $I / \mathrm{A}$ in GCD & $\mathrm{d} E / \mathrm{d} t / \mathrm{V} \cdot \mathrm{s}^{-1}$ in CV \\
\hline 0.09283 & 0.001 & 0.011 \\
0.09283 & 0.1 & 1.077 \\
0.09283 & 1 & 10.772 \\
1 & 0.1 & 0.1 \\
1 & 1 & 1 \\
1 & 10 & 10 \\
10 & 0.1 & 0.01 \\
10 & 1 & 0.1 \\
10 & 10 & 1 \\
100 & 0.1 & 0.001 \\
100 & 1 & 0.01 \\
100 & 10 & 0.1 \\
500 & 0.1 & 0.0002 \\
500 & 1 & 0.002 \\
500 & 10 & 0.02 \\
\hline
\end{tabular}

The significant difference between the calculated mass based on the deposition charge and the gravimetrically determined one has been observed before [96]; a conclusive explanation has not been found yet. Double layer or electrode capacities were determined for $\mathrm{MnO}_{2}$ electrodes in an aqueous $0.1 \mathrm{M} \mathrm{Na}_{2} \mathrm{SO}_{4}$ (Riedel de Haën, p.A.) electrolyte solution using cyclic voltammetry at various scan rates, galvanostatic charge/discharge measurements, and electrode impedance measurements.

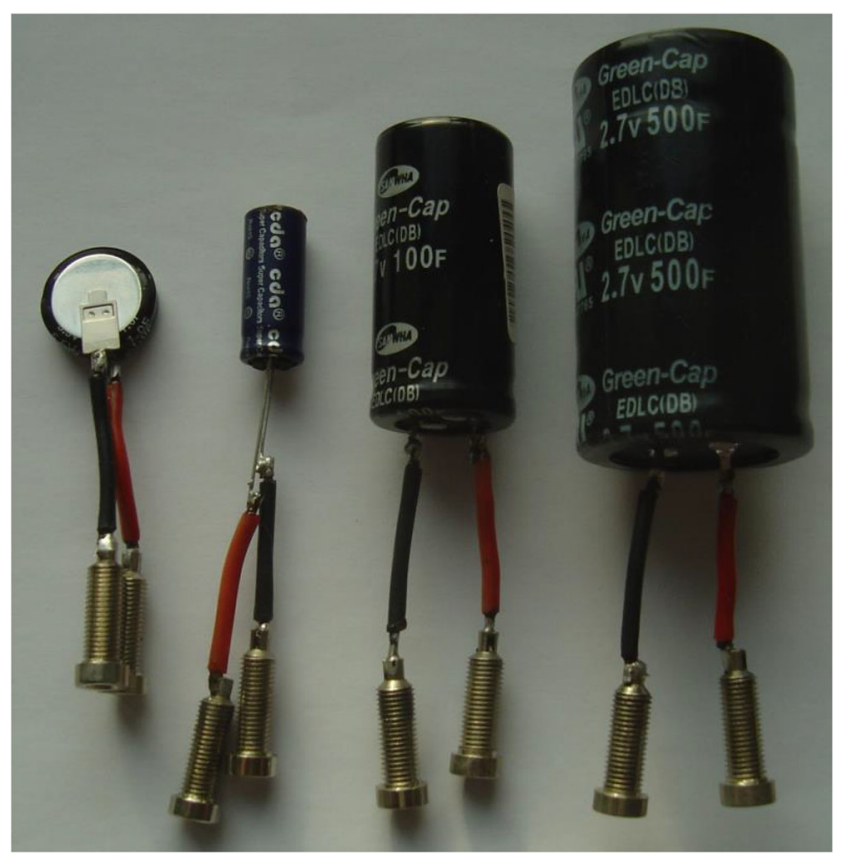

Fig. 3 Examined supercapacitors

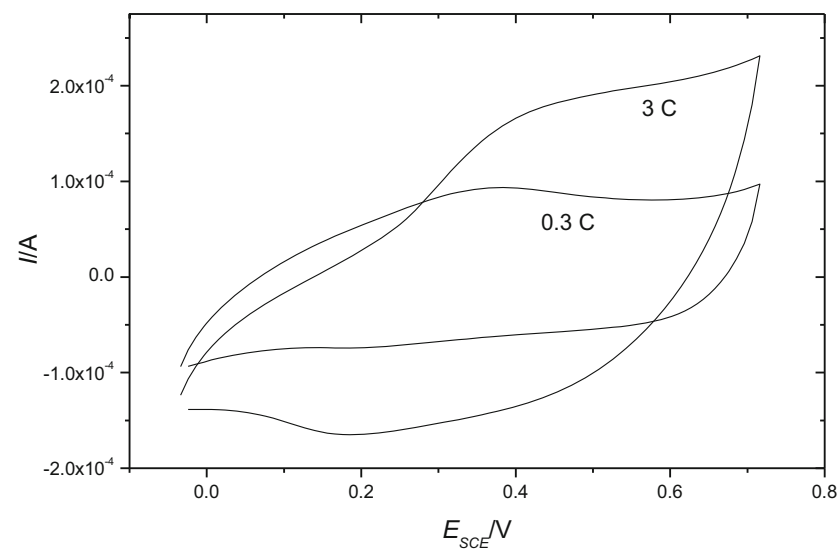

Fig. $4 \mathrm{CVs}$ of $\mathrm{MnO}_{2}$ electrodes with different loadings in an aqueous 0.1 M Na $2 \mathrm{SO}_{4}$ electrolyte solution at $\mathrm{d} E / \mathrm{d} t=0.005 \mathrm{~V} \mathrm{~s}^{-1}$

Cyclic voltammetry (CV) and galvanostatic charge/ discharge (GCD) measurements were performed on a potentiostat IVIUMSTAT Electrochemical Interface within the electrode potential window $-0.034<E_{\mathrm{SCE}}<0.766 \mathrm{~V}$ at scan rates and currents listed below. Scan rates and currents were adjusted to corresponding values; i.e. currents registered in CVs were used as charging/discharging currents in GCD. Table 2 provides examples of related numbers. In experiments attention was paid to run measurements at corresponding values because of the expected dependencies of observed capacitance on rate of change of the state of charge.

For electrochemical impedance measurements (single electrodes in three-electrode arrangement potentiostatically) said IVIUMSTAT Electrochemical Interface was also employed. The measurements at electrodes were carried out at the electrode potential where in preceding CVs current readings (approximately in the middle of the electrode potential window) were taken with a modulation amplitude of $5 \mathrm{mV}$ in the frequency range from 0.1 to $10^{5} \mathrm{~Hz}$. Evaluation of the impedance data was performed with IviumSoft and Boukamp V. 2.4 software.

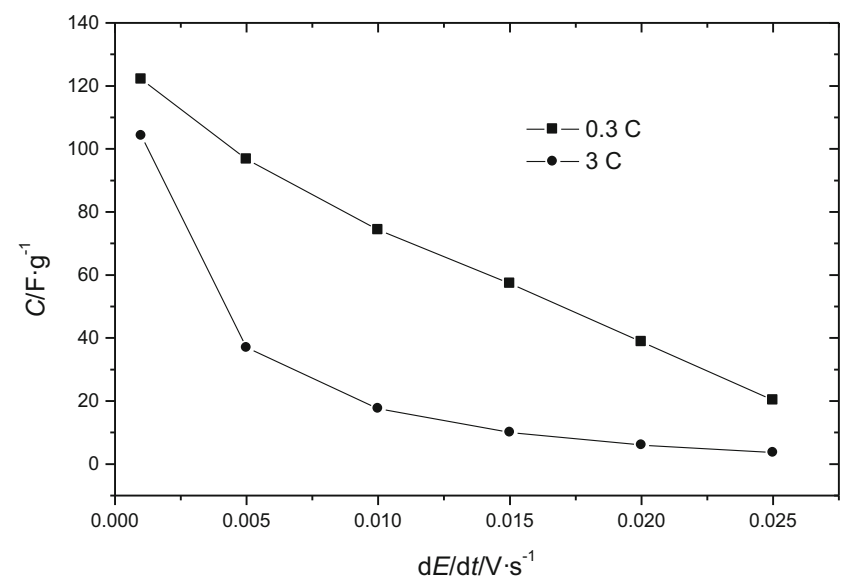

Fig. 5 Capacitances of $\mathrm{MnO}_{2}$ electrodes with different loadings in contact with an aqueous solution of $0.1 \mathbf{M ~ N a}_{2} \mathrm{SO}_{4}$ electrolyte solution at different scan rates 


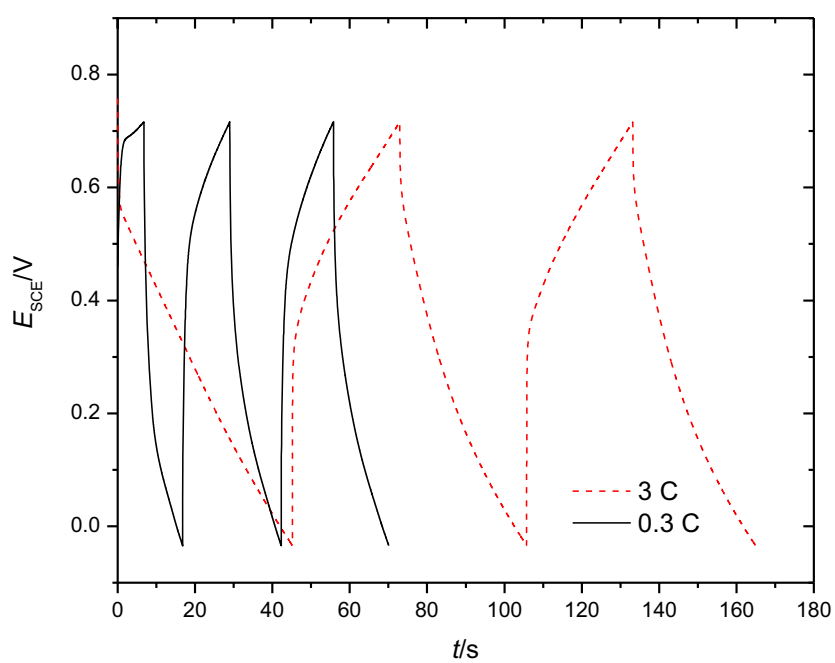

Fig. 6 GCD curves $\mathrm{MnO}_{2}$ electrodes at different loadings given as deposition charges as indicated at $1 \mathrm{~A} \mathrm{~g}^{-1}$

\section{Supercapacitor measurements}

Supercapacitors (1 F, 100 F, 500 F, SANWHA GreenCap, 10 F, cda, series CXHP; see Fig. 3) and for comparison an electrolytic capacitor $(2200 \mu \mathrm{F}, \mathrm{ELNA})$ were acquired from commercial distributors.

Their capacities were measured galvanostatically at various currents and at voltage scan rates corresponding to these currents (see Table 2) on a potentiostat IVIUMSTAT Electrochemical Interface between 0.5 and $1.5 \mathrm{~V}$ cell voltages, i.e., within the operating voltage range specified by the manufacturer. Cell impedances were measured with the instrumentation described in the previous section; evaluation was done with Boukamp software (version 2.4) and for corroboration with IviumSoft software. AC currents were adjusted depending on the measured capacitance to obtain a voltage

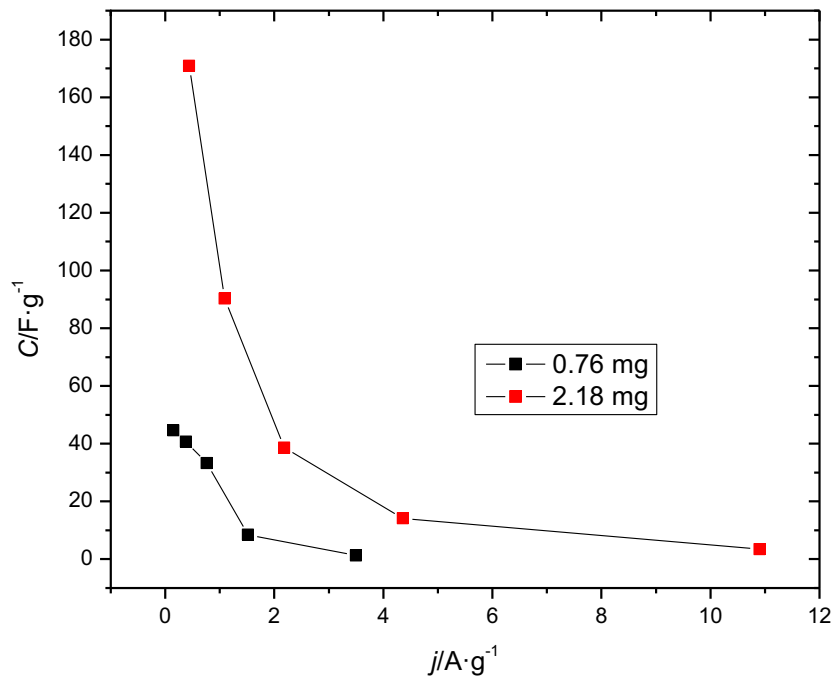

Fig. 7 Capacitances of $\mathrm{MnO}_{2}$ electrodes with different loadings in contact with an aqueous solution of $0.1 \mathrm{M} \mathrm{Na}_{2} \mathrm{SO}_{4}$ electrolyte solution at different current densities

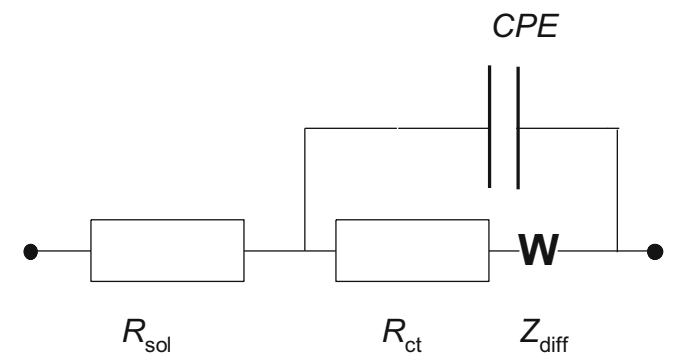

Fig. 8 Equivalent circuit used for fitting of electrode impedances

response sufficiently above the noise level. Excessive currents and associated Joule heating of the capacitors were avoided.

\section{Results and discussion}

\section{Electrode measurements}

Dependencies of numerical values of the interfacial capacitance (both double layer $C_{\mathrm{DL}}$ and pseudocapacitance due to superficial redox reactions) on charging/discharging current and scan rate are well known. For several reasons, in particular because of the limited speed of diffusing ions which are needed for charge compensation at the electrochemical interface, utilization of the electrochemical interface area inside porous structures (inner electrode surface area) decreases with growing scan rate. This is commonly called capacitance retention with a higher retention suggesting generally better performance, specifically more capacitance obtained even at higher currents and scan rates. Using $\mathrm{RuO}_{2}$ as an example has been studied by Ardizzone et al. [33]. As a result from suitable plots, the charge related to the outer and the inner surface and finally the total surface area were obtained. Substituting $C_{\mathrm{DL}}$ instead of charge the plots, relationships and results are:

$C_{\mathrm{DL}, \text { tot }}=C_{\mathrm{DL}, \text { inn }}+C_{\mathrm{DL}, \text { out }}$

$C_{\mathrm{DL}, \text { tot }}$ from extrapolation of $1 / C_{\mathrm{DL}}$ vs. $(\mathrm{d} E / \mathrm{d} t)^{1 / 2}$

$C_{\mathrm{DL}, \text { out }}$ from extrapolation of $C_{\mathrm{DL}} \mathrm{vs} .(\mathrm{d} E / \mathrm{d} t)^{-1 / 2}$

$C_{\mathrm{DL}, \text { inn }}=C_{\mathrm{DL}, \text { tot }}-C_{\mathrm{DL}, \text { out }}$

At first glance, this distinction seems to be irrelevant in the present context because in almost all publication an electrode capacity (or capacitance) is reported without regard to the details discussed above. Quite obviously the actually reported values depend on the applied scan rate. Because frequently

Table 3 Impedance data obtained with $\mathrm{MnO}_{2}$ electrodes with two different loadings using the equivalent circuit depicted in Fig. 8.

\begin{tabular}{llllll}
\hline Loading $/ \mathrm{C}$ & $R_{\mathrm{sol}} / \Omega$ & $Q / \mathrm{F} \cdot \mathrm{s}^{1-\mathrm{n}}$ & $\mathrm{n} /-$ & $R_{\mathrm{ct}} / \Omega$ & $\sigma / \Omega \cdot \mathrm{s}^{-1 / 2}$ \\
\hline 0.3 & 4.6 & $3.6 \cdot 10^{-4}$ & 1 & 209 & 0.0115 \\
3 & 4.7 & $1.2 \cdot 10^{-3}$ & 1 & 112 & 0.0146 \\
\hline
\end{tabular}


Fig. 9 Modified equivalent circuits used for fitting of electrode impedances.

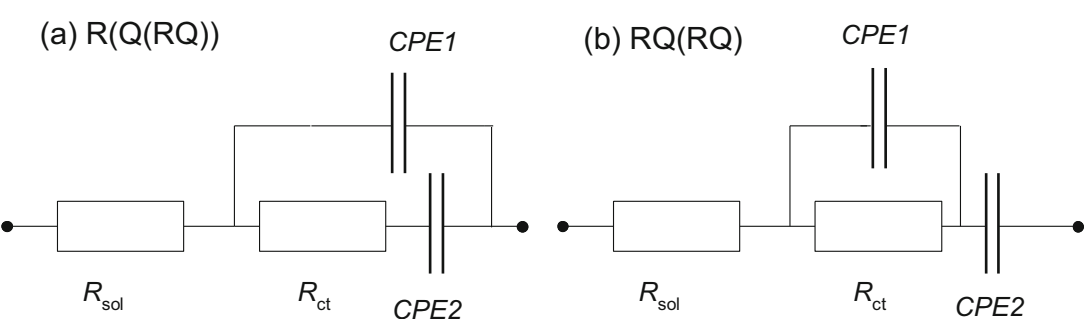

rate capabilities and/or capacity retentions are reported, authors must be aware of this dependency. In the absence of a generally accepted "standard" or "reference" scan rate, it seems appropriate to use $C_{\mathrm{DL} \text {,tot }}$ as obtained by the procedure first suggested by Ardizzone et al. [33]. Because this value is obtained by extrapolation of experimental data to the limiting case of zero scan rate, it is called $C_{\max }$ here. Typical CVs of the $\mathrm{MnO}_{2}$-coated steel mesh electrode with different loadings are shown in the following picture (Fig. 4).

Capacitances were calculated from currents observed in the $\mathrm{CVs}$ at various scan rates ranging from 1 to $25 \mathrm{mV} \cdot \mathrm{s}^{-1}$; results are collected in Fig. 5.

Evaluation of the data obtained with the electrode having a smaller loading yielded a value of $C_{\max }=180 \mathrm{~F} \cdot \mathrm{g}^{-1}$. This value is in good agreement with values calculated from the redox storage capability of $\mathrm{MnO}_{2}$ and an electrode potential variation similar to the one employed here. For a thorough discussion of theoretical capacities and mass utilization, see [42]. For the electrode with the higher loading $C_{\max }=330 \mathrm{~F} \cdot \mathrm{g}^{-1}$ was obtained. Already these data suggest that reporting of capacitance values for an electrode/an electrode material at just one scan rate is of limited value only, in particular when trying to compare data with results of other studies or with a theoretical capacitance frequently invoked [42].

$\mathrm{Hu}$ and Tsou used only CV in their study, whereas in most supercapacitor electrode studies, GCD measurements are used. We have used both methods in a closely corresponding way as described above. A typical result for both loadings is shown in Fig. 6; all results are collected in Fig. 7.

Again the obvious dependency of the obtained capacitance on current densities suggests extrapolation to zero current density. Evaluation yielded $C_{\max }=170 \mathrm{~F} \mathrm{~g}^{-1}$ and $C_{\max }=422 \mathrm{~F} \mathrm{~g}^{-1}$ for the electrodes with loadings 0.3 and $3 \mathrm{C}$, respectively. The values agree with those reported above for $\mathrm{CV}$ or are at least close to them.

Table 4 Impedance data obtained with $\mathrm{MnO}_{2}$ electrodes with two different loadings using the equivalent circuit depicted in Fig. $9 \mathrm{~b}$

\begin{tabular}{lllllll}
\hline Loading/C & $R_{\text {sol }} / \Omega$ & $Q 1 / \mathrm{F} \mathrm{s}^{1-} \mathrm{ng}^{-1}$ & $\mathrm{n} 1 /-$ & $R_{\mathrm{ct}} / \Omega$ & $Q 2 / \mathrm{F} \mathrm{s}^{1-\mathrm{n}} \mathrm{g}^{-1}$ & $\mathrm{n} 2 /-$ \\
\hline 0.3 & 3.4 & 65 & 0.95 & 150 & 1.2 & 0.6 \\
3 & 3.7 & 50 & 1 & 240 & 2 & 0.6 \\
\hline
\end{tabular}

Impedance measurements with these electrodes were conducted potentiostatically. Evaluation was done using equivalent circuits. Given the porous morphology of the investigated electrodes, use of a simple circuit based on the Randles circuit [97] even after incorporation of a diffusion contribution may be considered insufficient; indeed, more elaborate circuits based on, e.g., transmission line models (see, e.g., a universal equivalent circuit in [98]) have been proposed and recommended. The most simple circuit providing a sufficiently good representation of the obtained data and yielding the desired information about the examined electrode may be considered as being satisfactory, nevertheless [80, 81]. This is standard procedure in practically all publications dealing with supercapacitor electrode materials. The caveat in [80, 81] that even the simplest circuit must take into account the already known processes at the electrochemical interface is frequently ignored. As already outlined above, basic standards of reporting are also ignored; indeed, the impression is supported that this approach is sufficient. For a typical example, see [99]. Accordingly in the initial try here, the equivalent circuit depicted in Fig. 8 was used; obtained results are collected in Table 3.

The exponent $n$ describing the non-ideality of the constant phase element CPE used instead of a simple capacity to model the double layer capacity is $n=1$; accordingly the value of $Q$ can be taken as the double layer capacity following the arguments assembled by Jovic [100] already discussed before [82].

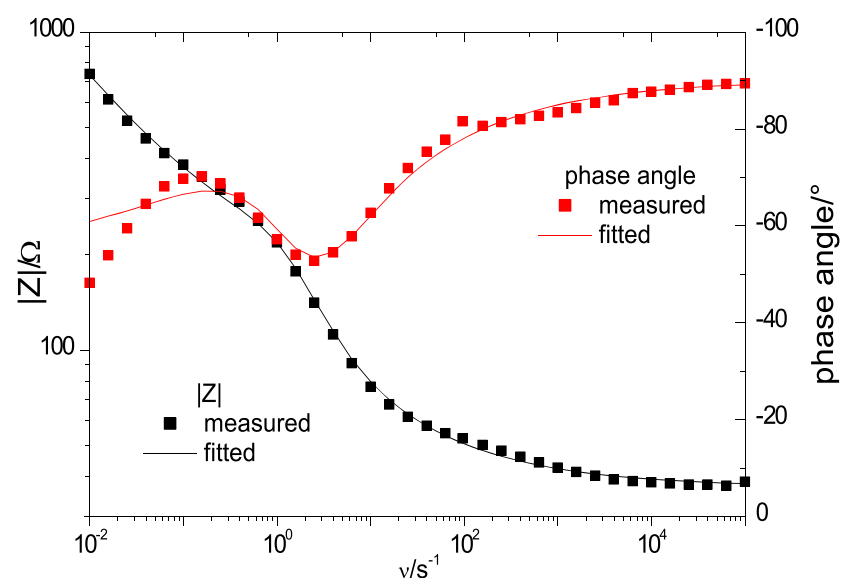

Fig. 10 Impedance results with equivalent circuit in Fig. $9 \mathrm{~b}$ in Bode display for an electrode with loading $0.3 \mathrm{C}$ 
Table 5 Capacitances of $\mathrm{MnO}_{2}$ electrodes

\begin{tabular}{lllll}
\hline Loading/C & mass & CV & GDC & Impedance \\
\hline 0.3 & $0.65 \mathrm{mg}$ & $180 \mathrm{~F} \cdot \mathrm{g}^{-1}$ & $170 \mathrm{~F} \cdot \mathrm{g}^{-1}$ & $65 \mathrm{~F} \cdot \mathrm{g}^{-1}$ \\
3 & $2.2 \mathrm{mg}$ & $330 \mathrm{~F} \cdot \mathrm{g}^{-1}$ & $422 \mathrm{~F} \cdot \mathrm{g}^{-1}$ & $50 \mathrm{~F} \cdot \mathrm{g}^{-1}$ \\
\hline
\end{tabular}

With a higher loading, a higher value of $C_{\mathrm{DL}}$ is observed. Taking the electrode masses, gravimetric capacitances of $0.55 \mathrm{~F} \mathrm{~g}^{-1}$ and $0.54 \mathrm{~F} \mathrm{~g}^{-1}$ were obtained. The similarity of the values does not necessarily suggest that the active mass utilization was independent of the loading; it might merely suggest that impedance measurements probed the same very small fraction of the electrode (penetration depth) in both cases [101]. The obtained values are lower by two orders of magnitude than values obtained with $\mathrm{CV}$ and GCD. Obviously the used equivalent circuit is inadequate. Certainly the decrease of the charge transfer resistance may be in part ascribed to the increased electrochemically active surface area EASA reflected in the larger value of the CPE. But a physical understanding of the diffusion element, and in particular the complete absence of any element representing the superficial redox processes assumed to be responsible for the charge storage, is disturbing. Unfortunately there seems to be no overview of methodological aspects of impedance measurements available. Even a report apparently answering the question asked here does not provide a single equivalent circuit or a description of it possibly useful in a practical application [102]. The electrode studied here closely resembles an electrode composed of an intrinsically conducting polymer deposited on an electronically conducting substrate. Such electrodes have been frequently suggested for electrochemical energy storage applications (for an overview, see [103]); they have been studied extensively with impedance measurements [104]. Following the considerations provided in the latter report, we have examined two modified equivalent circuits depicted in Fig. 9.

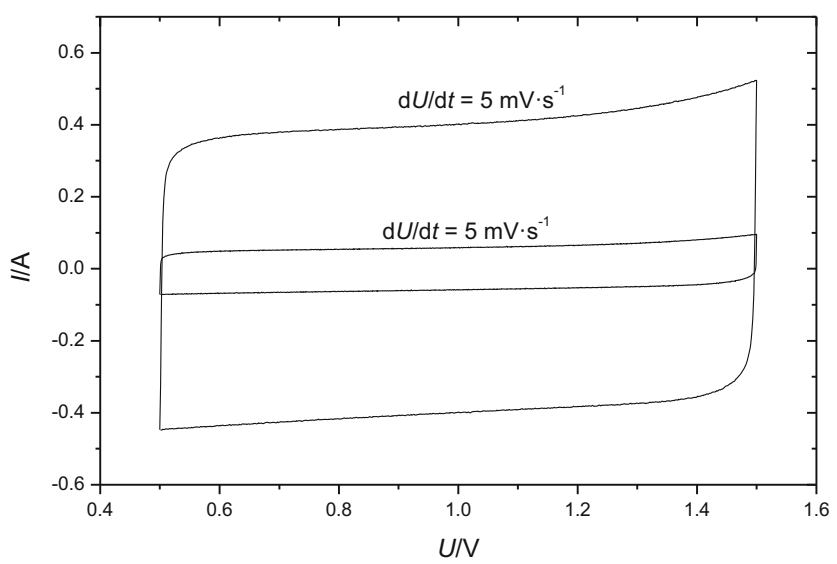

Fig. $11 \mathrm{CVs}$ of a supercap $100 \mathrm{~F}$ at scan rates as indicated

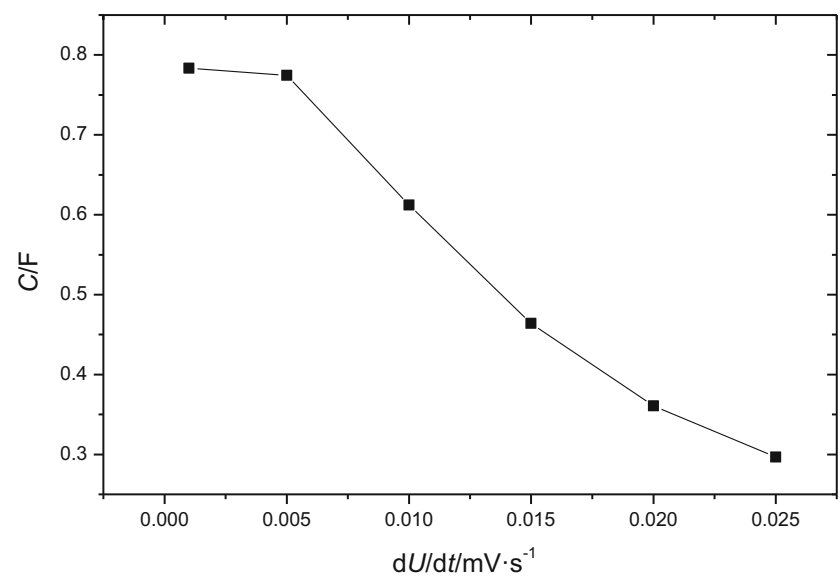

Fig. 12 Capacitance of a $1 \mathrm{~F} \mathrm{SC}$ as a function of scan rate

Circuit a in Fig. 9 is based on the model of an electrode wherein the double layer capacitance represented as CPE1 is established in parallel to the electrode reaction wherein the charge transfer represented by $R_{\mathrm{ct}}$ feeds into the metal oxide storage material undergoing redox changes represented by CPE2. In case $\mathrm{n} 2$ is found to be 1 , this element turns into a simple capacitance resembling the adsorption capacitance applied elsewhere [105]. Circuit b in Fig. 9 is based on a model where the double layer capacity (CPE1) is found in parallel to $R_{\mathrm{ct}}$ with the redox-active material CPE2 acting as the electrode (material). Based on the consistently better fit with circuit $\mathrm{b}$ (which also agrees with the circuit used for the polymercoated electrode before [104]; a typical result is shown in Fig. 10), results obtained with circuit $b$ are listed in Table 4 (averages of repeated measurements with two electrodes each).

The bigger CPE1 is assigned to the redox-active $\mathrm{MnO}_{2}$ storage material. The smaller CPE2 is related to the interfacial double layer capacitance. The associated value of $n$ differs strongly from 1 indicating a highly non-ideal capacitance typical of such highly porous material.

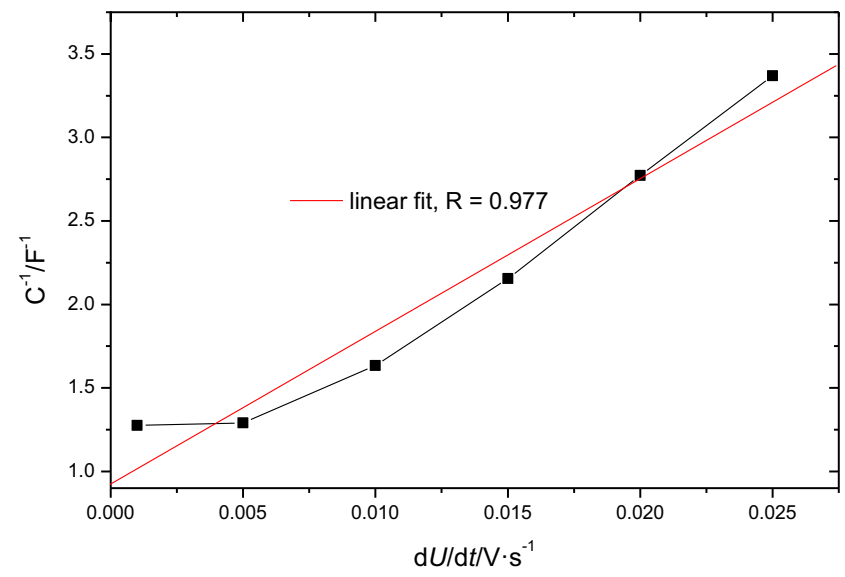

Fig. 13 Plot of $1 / C$ vs. scan rate for the $1 \mathrm{~F} \mathrm{SC}$ 
Table 6 Capacitance values $C_{\max }$ of supercaps determined by extrapolation

\begin{tabular}{lllll}
\hline Nominal capacity & $1 \mathrm{~F}$ & $10 \mathrm{~F}$ & $100 \mathrm{~F}$ & $500 \mathrm{~F}$ \\
\hline$C_{\max }$ & $1.1 \mathrm{~F}$ & $8.6 \mathrm{~F}$ & $82 \mathrm{~F}$ & $657 \mathrm{~F}$ \\
\hline
\end{tabular}

The results obtained with both $\mathrm{MnO}_{2}$ electrodes and three independent methods are collected in Table 5 .

The capacitances obtained with higher loadings show higher capacitances than the estimated theoretical capacitance values as discussed. Given the various experimental uncertainties, this deviation is significant and may require further examination. The conclusion at this point: reporting capacitances just for one arbitrarily selected scan rate or current density is insufficient for a valid comparison. Values from $\mathrm{CV}$ and GCD agree reasonably well. Values obtained by impedance measurements are significantly too low. This may possibly be due to the limited "penetration depth" of this method [80, 81, 101]; the similarity of the values suggests this assumption. Studies with thinner electrodes may help to confirm this, until this discrepancy can be explained impedance measurements may be less suitable than $\mathrm{CV}$ and GCD for capacitance determination.

\section{Supercapacitor measurements}

Measurements of the capacitance of supercapacitors (i.e., complete cells) as a function of charging parameters have been performed potentiostatically, galvanostatically, and with impedance measurements. Typical results of CV are shown in Fig. 11.

A dependency of the measured capacitance on the scan rate becomes obvious in Fig. 12

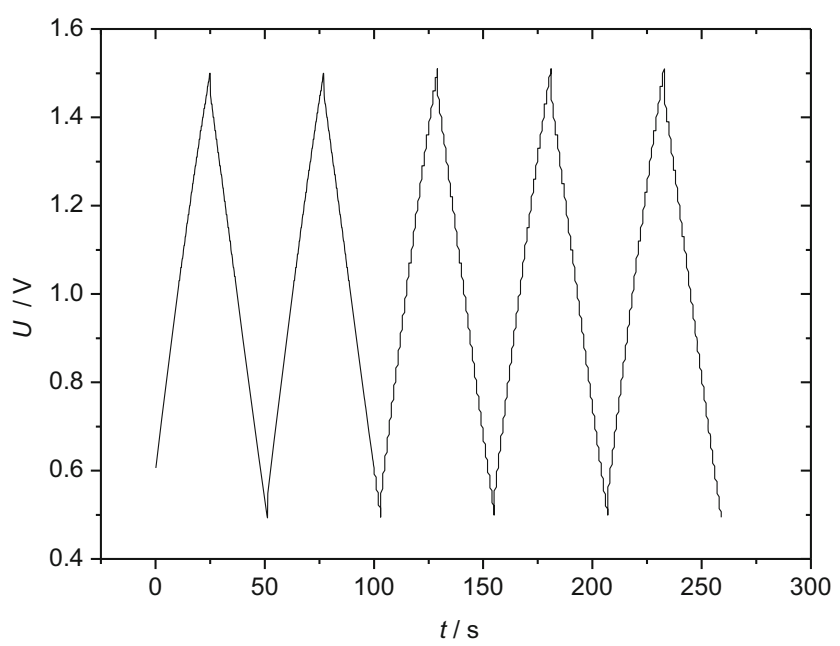

Fig. 14 Charge/discharge display of a supercap of $100 \mathrm{~F}$ at $I=5 \mathrm{~A}$.

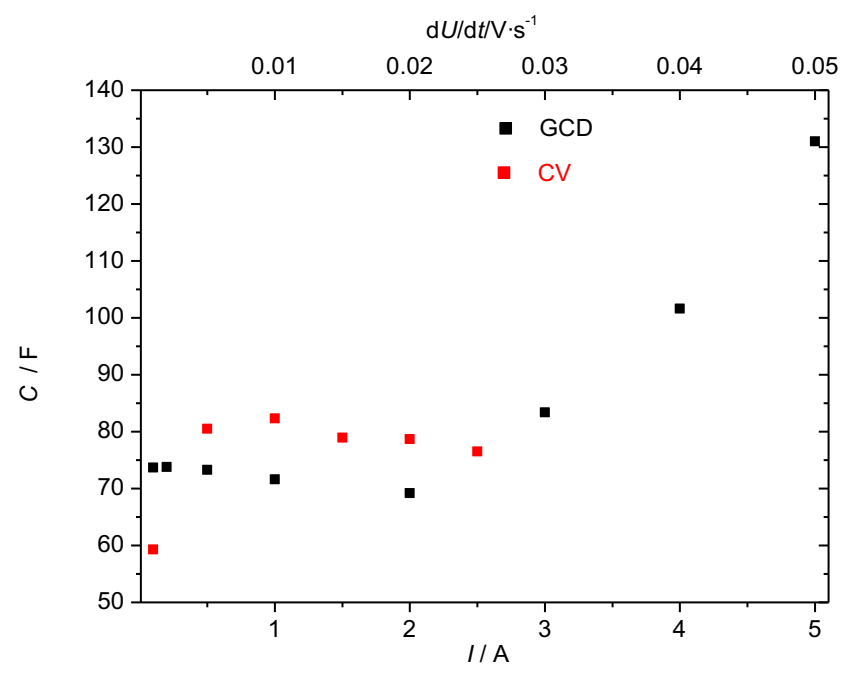

Fig. 15 Capacitance of a supercap $100 \mathrm{~F}$ at different charge/discharge currents and different voltage scan rates

Extrapolation to zero scan rate as shown in Fig. 13 yields the rated capacitance value $C=1.08 \mathrm{~F}$ within the manufacturers tolerance. The same procedure applied to the other SCs in this study yielded similar results, although the dependencies were differently pronounced.

Results for all examined supercaps are collected in Table 6

Figure 14 shows a typical dataset from charge/discharge experiments with a supercap of $100 \mathrm{~F}$ at $I=5 \mathrm{~A}$.

The capacitance $C$ calculated as $C=\left(t_{\mathrm{dis}} \cdot I\right) / \Delta U$ shows a noticeably dependence of the capacitance on the charge/ discharge current and the voltage scan rate (Fig. 15).

The dependencies are better visible with a SC of $1 \mathrm{~F}$ in Fig. 16.

Determination of $C_{\max }$ by extrapolation yielded the values collected in Table 7.

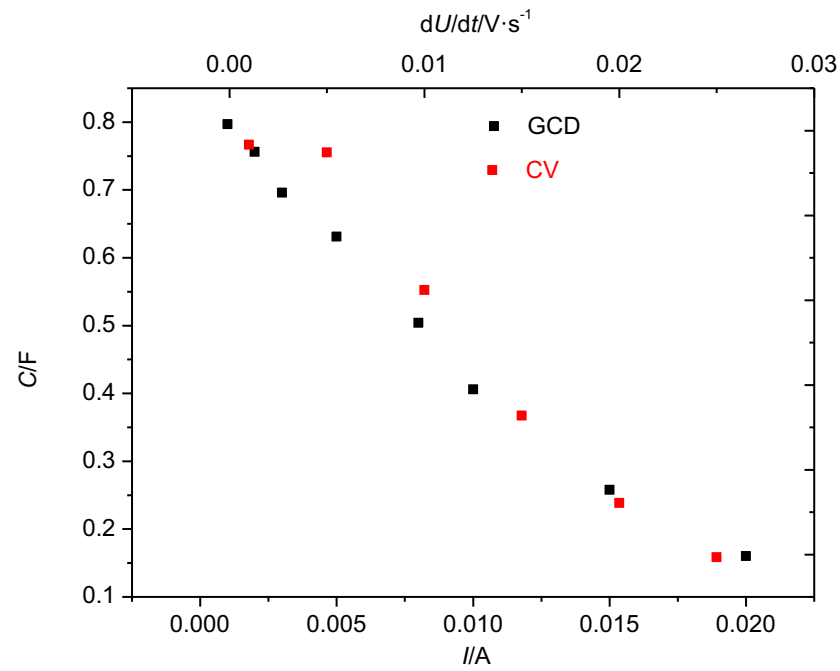

Fig. 16 Capacitance of a supercap $1 \mathrm{~F}$ at different charge/discharge currents and different voltage scan rates 
Table 7 Capacitance values $C_{\max }$ of supercaps determined by extrapolation

\begin{tabular}{lcccc}
\hline Nominal capacity & $1 \mathrm{~F}$ & $10 \mathrm{~F}$ & $100 \mathrm{~F}$ & $500 \mathrm{~F}$ \\
\hline$C_{\max }$ & $0.9 \mathrm{~F}$ & $8.9 \mathrm{~F}$ & $75.5 \mathrm{~F}$ & $429 \mathrm{~F}$ \\
\hline
\end{tabular}

\section{Impedance}

Impedances measured galvanostatically at a current large enough to provide a response with an acceptable signal-tonoise ratio and small enough to avoid heating of the studied supercapacitor were evaluated assuming a simple RC equivalent circuit. In a few cases depending on cabling, setup, and studied supercap, very small inductivities possibly caused either by the internal construction of the supercap or the experimental setup were noticed. Results are collected in Table 8 . Independent measurement and evaluation by fitting using a potentiostat Gamry Reference 3000 with associated software yielded a capacitance of $353 \mathrm{~F}$ for the commercial supercap rated at $500 \mathrm{~F}$.

Typical results of measured and fitted impedance data are shown below for two supercaps in Fig. 17 and 18.

Applicability of the selected model (whether an equivalent circuit as done here or a transfer function [82]) must always be critically examined after fitting by comparing measured and fitted data; in addition, comparison with results of other methods must be considered $[80,81,101,106]$. The displayed examples show a satisfactory agreement of fit and measurement. This conclusion is in complete agreement with an earlier report [32]. The need for a constant phase element CPE used instead of a simple capacitor was not observed; the frequently observed general improvement of the quality of the fit with a CPE was not found here. The need to find a proper relation between the double layer capacity and the value of the CPE highlighted elsewhere was thus avoided [17, 82]. The value of the series resistance $R$ obtained from the impedance measurements is not listed because the values, which are commonly associated with the sum of all Ohmic components and contributions in the electric pathway between the connectors contains beyond the possibly interesting value of ESR also contributions from electric contact to the supercap under examination. Except for the button-type $1 \mathrm{~F}$ supercap all other supercaps had $R$ values below $10 \mathrm{~m} \Omega$.

A comparison of the results obtained with impedance measurements with those obtained with $\mathrm{CV}$ and GCD (see

Table 8 Results of impedance measurements of commercial supercapacitors

\begin{tabular}{lllll}
\hline Nominal capacity & $1 \mathrm{~F}$ & $10 \mathrm{~F}$ & $100 \mathrm{~F}$ & $500 \mathrm{~F}$ \\
\hline Measured capacity & $0.46 \mathrm{~F}$ & $7.45 \mathrm{~F}$ & $67 \mathrm{~F}$ & $363 \mathrm{~F}$ \\
\hline
\end{tabular}

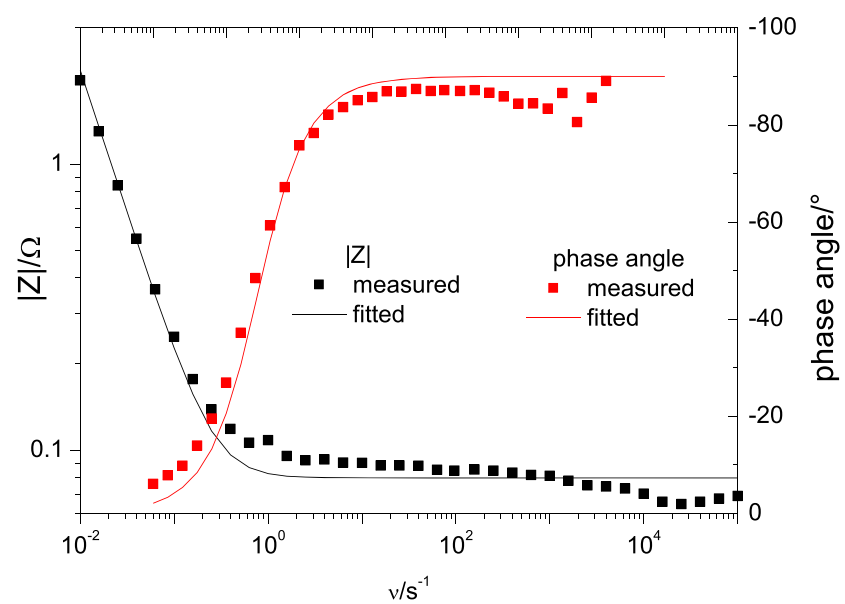

Fig. 17 Impedance results in Bode display for a supercap $10 \mathrm{~F}$

Table 9) should be based on the values of $C_{\max }$ obtained with the latter methods. In case of devices showing very good rate capability, i.e., hardly a decrease in energy density with increasing power density in a Ragone diagram indicative of very high mass utilization, optimized ionic, and electronic current transport and a low ESR, $C_{\max }$ will not differ much from values found at higher currents and larger scan rates. Nevertheless, this rate dependency should be examined before making the comparison.

Results obtained by three independent methods with specimen showing nominal capacities varying over almost three orders of magnitude show good agreement with only the supercaps of $1 \mathrm{~F}$ and $500 \mathrm{~F}$ showing enlarged scattering of the results. In the former case, this may be due to different mechanical construction (button type) and the rather large Ohmic series resistance negatively affecting the fit (uncertainty of C was largest with this supercap). Causes for the scatter observed with the $500 \mathrm{~F}$ supercap are not obvious. The particularly disturbing large $C_{\max }$ value obtained by $\mathrm{CV}$ is possibly due to instrumental limitations. Measurements of the electrolytic capacitor performed as a reference only confirmed the general trends observed here.

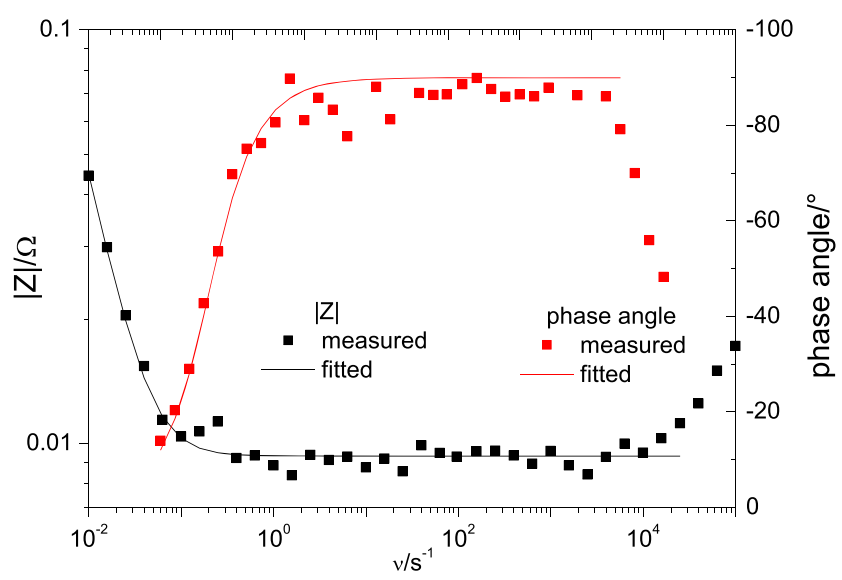

Fig. 18 Impedance results in Bode display for a supercap $500 \mathrm{~F}$ 
Table 9 Comparison of results of CV, GCD, and impedance measurements of commercial supercapacitors

\begin{tabular}{lllll}
\hline Nominal capacity & $1 \mathrm{~F}$ & $10 \mathrm{~F}$ & $100 \mathrm{~F}$ & $500 \mathrm{~F}$ \\
\hline $\mathrm{CV}, C_{\max }$ & $1.1 \mathrm{~F}$ & $8.6 \mathrm{~F}$ & $82 \mathrm{~F}$ & $657 \mathrm{~F}$ \\
$\mathrm{GCD}, C_{\max }$ & $0.9 \mathrm{~F}$ & $8.9 \mathrm{~F}$ & $75.5 \mathrm{~F}$ & $429 \mathrm{~F}$ \\
Impedance & $0.46 \mathrm{~F}$ & $7.45 \mathrm{~F}$ & $67 \mathrm{~F}$ & $363 \mathrm{~F}$ \\
\hline
\end{tabular}

\section{Conclusions}

Comparison of supercap electrodes, electrode materials, and device capacitance values obtained with $\mathrm{CV}$ and GCD should always be based on extrapolated values obtained assuming zero scan rate and zero current. Otherwise, the well-known effect of non-ideal capacitance retention frequently made visible in Ragone plots might affect a fair comparison. This applies in particular when comparison with impedance results is included. The latter method seems to have limitations with single electrode measurements.

Acknowledgements Preparation of this communication has been supported in various ways by the Alexander von Humboldt-Foundation, Deutscher Akademischer Austauschdienst, Fonds der Chemischen Industrie, Deutsche Forschungsgemeinschaft, National Basic Research Program of China, and Natural Science Foundation of China. It includes results obtained within a research project at St. Petersburg State University supported by grant № 26455158. One of us (Y.G.) is grateful for the financial support from China Scholarship Council. Experimental assistance in acquiring impedance data of supercapacitors by C. Lämmel and M. Schneider as well as helpful discussions on this subject with J. Miller, C. Lämmel and M. Schneider are appreciated.

Funding information Open Access funding provided by Projekt DEAL

Open Access This article is licensed under a Creative Commons Attribution 4.0 International License, which permits use, sharing, adaptation, distribution and reproduction in any medium or format, as long as you give appropriate credit to the original author(s) and the source, provide a link to the Creative Commons licence, and indicate if changes were made. The images or other third party material in this article are included in the article's Creative Commons licence, unless indicated otherwise in a credit line to the material. If material is not included in the article's Creative Commons licence and your intended use is not permitted by statutory regulation or exceeds the permitted use, you will need to obtain permission directly from the copyright holder. To view a copy of this licence, visit http://creativecommons.org/licenses/by/4.0/.

\section{References}

1. Zhi M, Xiang C, Li J, Li M, Wu N (2013) Nanostructured carbonmetal oxide composite electrodes for supercapacitors: A review. Nanoscale 5(1):72-88

2. Lippmann G (1875) Relations entre les phénoménes électriques et capillaries. Ann Chim Phys 5:494-549

3. see also: Bockris JO’M, Reddy AKN, Gamboa-Aldeco M (2000) Modern electrochemistry, vol. 2A. Kluwer-Plenum, New York, $\mathrm{p}$ 858,875
4. Perrin JB (1903) Traité de chimie physique. Les principes

5. Stern O (1924) The theory of the electrolytic double-layer. Z Elektrochem 30:508-516

6. Gouy G (1909) Constitution of the electric charge at the surface of an electrolyte. CR Acad Sci 149:654-657

7. Gouy G (1906) Sur la fonction électrocapillaire III. Ann Chim Phys 9:75-139

8. Gouy G (1910) Sur la constitution de la charge électrique à la surface d'un électrolyte (On the constitution of the electric charge on the surface of an electrolyte). J Phys 9:457-468

9. Chapman DL (1913) A contribution of the theory of capillarity. Philos Mag 25:475-481

10. de Levie R (2000) What's in a Name? J Chem Educ 77(5):610 612

11. Helmholtz HLF (1879) Studien über electrische Grenzschichten (Studies of electric boundary layers). Wied Ann 7:337-382

12. Grahame DC (1947) The electrical double layer and the theory of electrocapillarity. Chem Rev 41(3):441-501

13. The electrochemical double layer, Proceedings volume 97-17 (1997) (C. Korzeniewski, B.E. Conway Eds.) The Electrochemical Society, Inc., Pennington

14. Schmickler W (2020) Double layer theory. J Solid State Electrochem. https://doi.org/10.1007/s10008-020-04597-z

15. Bazant MZ, Thornton K, Ajdari A (2004) Diffuse-charge dynamics in electrochemical systems. Phys Rev B 70(2):021506

16. Yang H, Bo Z, Shuai X, Yan J, Cen K (2019) Influence of Wettability on the Charging Dynamics of Electric Double-Layer Capacitors. Acta Phys -Chim Sin 35(2):200-207

17. Xie X, Holze R Electrode kinetic data: Geometric vs. real surface area, submitted

18. Leiva E, Schmickler W (1986) New theories for the electric double layer at a metal/electrolyte solution interface. Proc Indian Acad Sci Chem Sci 97:267-296

19. Parsons R (1990) Electrical Double Layer: Recent Experimental and Theoretical Developments. Chem Rev 90(5):813-826

20. Conway BE, Birss V, Wojtowicz J (1997) The role and utilization of pseudocapacitance for energy storage by supercapacitors. J Power Sources 66(1-2):1-14

21. Moynihan JD (1982) Theory, Design and Application of Electrolytic Capacitors

22. Thiesbürger KH (1991) Der Elektrolyt-Kondensator, 4th edn. Roederstein, Landshut

23. Becker HI US-Patent US2800616, 23.07.1957

24. Rightmire RA US-Patent US3288641, 29.11.1966

25. Currie JC DiFranco LF, Bennett PD (1988) US-Patent US4730239, 08.03.1988

26. Wang W, Guo S, Lee I, Ahmed K, Zhong J, Favors Z, Zaera F, Ozkan M, Ozkan CS (2014) Hydrous Ruthenium Oxide Nanoparticles Anchored to Graphene and Carbon Nanotube Hybrid Foam for Supercapacitors. Sci Rep 4:4452

27. Holze R (2017) From current peaks to waves and capacitive currents-on the origins of capacitor-like electrode behavior. J Solid State Electrochem 21(9):2601-2607

28. Ragoisha GA, Aniskevich YM (n.a.) False capacitance of supercapacitors. arXiv1604.08154v1

29. Bard AJ, Faulkner LR (2001) Electrochemical Methods, 2nd edn Wiley, New York

30. Plambeck JA (1982) Electroanalytical chemistry. Wiley, New York

31. Wang J (2006) Analytical Electrochemistry. WILEY-VCH, Hoboken

32. Anonymous (2011) Autolab Application Note SC01, 01.07.2011

33. Ardizzone S, Fregonara G, Trasatti S (1990) "Inner" and "outer" active surface of $\mathrm{RuO}_{2}$ electrodes. Electrochim Acta 35(1):263269 
34. Vogt H (1994) Note on a method to interrelate inner and outer electrode areas. Electrochim Acta 39(13):1981-1983

35. Baronetto D, Krstajic N, Trasatti S (1994) Reply to "Note on a method to interrelate inner and outer electrode areas" by H. Vogt. Electrochim Acta 39(16):2359-2362

36. Anonymous (2017) Technical Note PS-5502 Eaton, Cleveland

37. Kundert K (2007) Modeling Dielectric Absorption in Capacitors. www.designers-guide.org, accessed 25.04.2020

38. Pease RA (1982) Understand capacitor soakage to optimize analog systems. EDN 13.10.1982:125-129; also at www.national. com/rap. Accessed 25 Apr 2020

39. Krishnan SG, Harilal M, Pal B, Misnon II, Karuppiah C, Yang CC, Jose R (2017) J Electroanal Chem 805:126-132

40. Gogotsi Y, Simon P (2001) True Performance Metrics in Electrochemical Energy Storage. Science 334:917-918

41. Jorne J (2018) C Rating of Batteries: A Misleading Concept C Flux Rather than C Rate. Interface 27(2):42-43

42. Ge Y, Liu Z, Wu Y, Holze R (2020) On the utilization of supercapacitor electrode materials. Submitted to Electrochim Acta

43. Stoller MD, Ruoff RS (2010) Best practice methods for determining an electrode material's performance for ultracapacitors. Energy Environ Sci 3(9):1294-1301

44. Lämmel C, Schneider M, Weiser M, Michaelis A (2013) Investigations of electrochemical double layer capacitor (EDLC) materials - a comparison of test methods. Mater Werkst 44(7): 641-649

45. Zhang S, Pan N (2015) Supercapacitors Performance Evaluation. Adv Energy Mater 5(6):1401401

46. Balducci A, Belanger D, Brousse T, Long JW, Sugimoto W (2017) A Guideline for Reporting Performance Metrics with Electrochemical Capacitors: From Electrode Materials to Full Devices. J Electrochem Soc 164(7):A1487-A1488

47. Ratha S, Samantara AK (2018) Supercapacitor: Instrumentation, Measurement and Performance Evaluation Techniques. Springer, Singapore

48. Kampouris DK, Ji X, Randviir EP, Banks CE (2015) A new approach for the improved interpretation of capacitance measurements for materials utilised in energy storage. RSC Adv 5(17): 12782-12791

49. Vielstich W, Schmickler W (1976) Elektrochemie II: Kinetik elektrochemischer Systeme (R. Haase Ed.). Steinkopff, Darmstadt

50. Gileadi E, Kirowa-Eisner E, Penciner J (1975) Interfacial Electrochemistry. Addison Wesley, London

51. Holze R, Schneider J, Hamann CH (1988) Eine neue Methode zur Untersuchung der Elektrosorption reaktiver Verbindungen. Ber Bunsenges Phys Chem 92(11):1319-1325

52. Doss KSG, Kalyanasundaram A (1952) Effect of surface active substances on the capacity of the electric double layer. Proc Indian Acad Sci 35A:27-33

53. Breyer B, Hacobian S (1952) Tensammetry: A Method of Investigating Surface Phenomena by AC Current Measurements. Aust J Sci Res Ser A 5:500-520

54. Holze R (2007) Landolt-Börnstein: Numerical Data and Functional Relationships in Science and Technology, New Series, Group IV: Physical Chemistry, Volume 9: Electrochemistry, Subvolume A: Electrochemical Thermodynamics and Kinetics, Martienssen W, Lechner MD, Eds., Springer, Berlin

55. Jehring H (1975) Elektrosorptionsanalyse mit der Wechselstrompolarographie. Akademie-Verlag, Berlin

56. Burke LD, Murphy OJ (1979) Cyclic voltammetry as a technique for determining the surface area of $\mathrm{RuO}_{2}$ electrodes. J Electroanal Chem 96(1):19-27

57. Hu CC, Chang KH, Lin MC, Wu YT (2006) Design and tailoring of the nanotubular arrayed architecture of hydrous $\mathrm{RuO}_{2}$ for next generation supercapacitors. Nano Lett 6(12):2690-2695
58. Wang J, Polleux J, Lim J, Dunn B (2007) Pseudocapacitive Contributions to Electrochemical Energy Storage in $\mathrm{TiO}_{2}$ (Anatase) Nanoparticles. J Phys Chem C 111(40):14925-14931

59. Sathiya M, Prakash AS, Ramesha K, Tarascon JM, Shukla AK (2011) $\mathrm{V}_{2} \mathrm{O}_{5}$-anchored carbon nanotubes for enhanced electrochemical energy storage. J Am Chem Soc 133(40):16291-16299

60. Ghosh A, Ra EJ, Jin M, Jeong HK, Kim TH, Biswas C, Lee YH (2011) High pseudocapacitance from ultrathin $\mathrm{V}_{2} \mathrm{O}_{5}$ films electrodeposited on self-standing carbon-nanofiber paper. Adv Funct Mater 21(13):2541-2547

61. Augustyn V, Come J, Lowe MA, Kim JW, Taberna PL, Tolbert SH, Abruña HD, Simon P, Dunn B (2013) High-rate electrochemical energy storage through $\mathrm{Li}^{+}$intercalation pseudocapacitance. Nat Mater 12:518-522

62. Lindström H, Södergren S, Solbrand A, Rensmo H, Hjelm J, Hagfeldt A, Lindquist SE (1997) $\mathrm{Li}^{+}$ion insertion in TiO2 (anatase). 2. Voltammetry on nanoporous films. J Phys Chem B 101(39):7717-7722

63. Sun HT, Mei L, Liang JF, Zhao ZP, Lee C, Fei HL, Ding MN, Lau J, Li MF, Wang C, Xu X, Hao GL, Papandrea B, Shakir I, Dunn B, Huang Y, Duan XF (2017) Three-dimensional holey-graphene/ niobia composite architectures for ultrahigh-rate energy storage. Science 356(6338):599-604

64. Augustyn V, Simon P, Dunn B (2014) Pseudocapacitive oxide materials for high-rate electrochemical energy storage. Energy Environ Sci 7(5):1597-1614

65. Chen X, Lv LP, Sun W, Hu Y, Tao X, Wang Y (2018) Ultrasmall $\mathrm{MoC}$ nanoparticles embedded in 3D frameworks of nitrogendoped porous carbon as anode materials for efficient lithium storage with pseudocapacitance. J Mater Chem A 6(28):13705-13716

66. Hou BH, Wang YY, Liu DS, Gu ZY, Feng X, Fan H, Zhang T, Changli L, Wu XL (2018) N-Doped Carbon-Coated $\mathrm{Ni}_{1.8} \mathrm{Co}_{1.2} \mathrm{Se}_{4}$ Nanoaggregates Encapsulated in N-Doped Carbon Nanoboxes as Advanced Anode with Outstanding High-Rate and LowTemperature Performance for Sodium-Ion Half/Full Batteries. Adv Funct Mater 28:1805444

67. Hu X, Peng Q, Zeng T, Shang B, Jiao X, Xi G (2019) Promotional role of nano $\mathrm{TiO}_{2}$ for pomegranate-like $\mathrm{SnS}_{2} @ \mathrm{C}$ spheres toward enhanced sodium ion storage. Chem Eng J 363:213-223

68. Fang G, Wu Z, Zhou J, Zhu C, Cao X, Lin T, Chen Y, Wang C, Pan A, Liang S (2018) Observation of Pseudocapacitive Effect and Fast Ion Diffusion in Bimetallic Sulfides as an Advanced Sodium-Ion Battery Anode. Adv Energy Mater 8(19):1703155

69. Lou S, Cheng X, Gao J, Li Q, Wang L, Cao Y, Ma Y, Zuo P, Gao Y, Du C, Huo H, Yin G (2018) Pseudocapacitive $\mathrm{Li}^{+}$intercalation in porous $\mathrm{Ti}_{2} \mathrm{Nb}_{10} \mathrm{O}_{29}$ nanospheres enables ultra-fast lithium storage. Energy Storage Mater 11:57-66

70. Opitz M, Yue J, Wallauer J, Smarsly B, Roling B (2015) Mechanisms of charge storage in nanoparticulate $\mathrm{TiO}_{2}$ and $\mathrm{Li}_{4} \mathrm{Ti}_{5} \mathrm{O}_{12}$ anodes: New insights from scan rate-dependent cyclic voltammetry. Electrochim Acta 168:125-132

71. Wang H, Pilon L (2012) Physical interpretation of cyclic voltammetry for measuring electric double layer capacitances. Electrochim Acta 64:130-139

72. Brousse T, Belanger D, Long JW (2015) To Be or Not To Be Pseudocapacitive? J Electrochem Soc 162(5):A5185-A5189

73. Simon P, Gogotsi Y, Dunn B (2014) Where Do Batteries End and Supercapacitors Begin? Science 343(6176):1210-2111

74. Dubal DP, Wu Y, Holze R (2016) Supercapacitors: from the Leyden jar to electric busses. ChemTexts 2:13

75. Fu L, Qu Q, Holze R, Kondratiev VV, Wu Y (2019) Composites of metal oxides and intrinsically conducting polymers as supercapacitor electrode materials: The best of both worlds? J Mater Chem A 7(25):14937-14970

76. Orazem ME, Tribollet B (2017) Electrochemical Impedance Spectroscopy, 2nd edn. Wiley, Hoboken 
77. Lasia A (2014) Electrochemical Impedance Spectroscopy and its Applications. Springer, New York

78. Yuan XZ, Song C, Wang H, Zhang J (2010) Electrochemical Impedance Spectroscopy in PEM Fuel Cells. Springer, London

79. Mei BA, Munteshari O, Lau J, Dunn B, Pilon L (2018) Physical Interpretations of Nyquist Plots for EDLC Electrodes and Devices. J Phys Chem C 122(1):194-206

80. Holze R (1983) Impedanzmessungen an porösen Elektroden; PhD-Dissertation; Universität Bonn

81. Holze R (1994) Electrode impedance measurements: A versatile tool for electrochemists. Bull Electrochem 10:56-67

82. Fu L, Qu Q, Holze R, Wu Y (2019) A comment on the need to distinguish between cell and electrode impedances. J Solid State Electrochem 23(3):717-724

83. Li Z, Yao Y, Zheng Y, Gao T, Liu Z, Zhou G (2018) Fabrication of Core-Shell Fe3O4@C@MnO2 Microspheres and Their Application in Supercapacitors. J Electrochem Soc 165(2):E58E63

84. Wang H, Pilon L (2012) Intrinsic limitations of impedance measurements in determining electric double layer capacitances. Electrochim Acta 63:55-63

85. Roling B, Drüschler M (2012) Comments on "Intrinsic limitations of impedance measurements in determining electric double layer capacitances" by H. Wang and L. Pilon [Electrochim. Acta 63 (2012) 55]. Electrochim Acta 76:526-528

86. Wang H, Pilon L (2012) Reply to comments on "Intrinsic limitations of impedance measurements in determining electric double layer capacitances" by H. Wang, L. Pilon [Electrochimica Acta 63 (2012) 55]. Electrochim Acta 76:529-531

87. Sedlakova V, Sikula J, Mazner J, Sedlak P, Kuparowtz T, Buergler B, Vasina P (2015) Supercapacitor equivalent electrical circuit model based on charges redistribution by diffusion. $\mathrm{J}$ Power Sources 286:58-65

88. Burke A, Miller M (2010) Testing of electrochemical capacitors: Capacitance, resistance, energy density, and power capability. Electrochim Acta 55(25):7538-7548

89. Zhang L, Wang Z, Hu X, Dorrell DG (2015) Experimental investigation of ultracapacitor impedance characteristics. Energy Procedia 75:1888-1894

90. DIN EN 62391-1:2016-09

91. Anonymous (2015) Application Note Rev. 2.0 4/27/2015 Gamry Instruments, Inc

92. ELV-Journal 13/1982, https://www.elv.de/controller.aspx?cid= $726 \&$ rol id $=4 \&$ spr id $=1 \&$ detail $=0 \&$ detail $2=2 \&$ PAGE $=$ $12 \&$ SORT $=\&$ search $=\&$ filter anfangsbuchstabe $=\mathrm{d} \&$ filter $j$ jahr $=$ $\&$ filter ausgabe $=$. Accessed 02 Apr 2020

93. Karden E, Buller S, De Doncker RW (2002) A frequency-domain approach to dynamical modeling of electrochemical power sources. ElectrochimActa 47(13-14):2347-2356
94. Stoller MD, Stoller SA, Quarles N, Suk JW, Murali S, Zhu Y, Zhu X, Ruoff RS (2011) Using coin cells for ultracapacitor electrode material testing. J Appl Electrochem 41(6):681-686

95. Hu CC, Tsou TW (2002) Ideal capacitive behavior of hydrous manganese oxide prepared by anodic deposition. Electrochem Commun 4(2):105-109

96. Winkler S, Holze R, unpublished results

97. Randles JEB (1947) Kinetics of Rapid Electrode Reactions. Faraday Discuss 1:11-19

98. Fletcher S, Black VJ, Kirkpatrick I (2014) A universal equivalent circuit for carbon-based supercapacitors. J Solid State Electrochem 18(5):1377-1387

99. Sakthivel M, Sukanya R, Chen SM, Pandi K, Ho KC (2019) Synthesis and characterization of bimetallic nickel-cobalt chalcogenides $\left(\mathrm{NiCoSe}_{2}, \mathrm{NiCo}_{2} \mathrm{~S}_{4}\right.$, and $\left.\mathrm{NiCo}_{2} \mathrm{O}_{4}\right)$ for non-enzymatic hydrogen peroxide sensor and energy storage: Electrochemical properties dependence on the metal-to-chalcogen composition. Renew Energy 138:139-151

100. Jović VD Determination of the correct value of $C_{\mathrm{dl}}$ from the impedance results fitted by the commercially available software. https://www.gamry.com/assets/Application-Notes/ Determination-of-Double-Layer-Capacitance-from-a-CPE.pdf; see also: https://www.gamry.com/application-notes/EIS/correctvalue-of-cdl/. Accessed 02 Apr 2020

101. Holze R, Vielstich W (1984) Double-Layer Capacity Measurements as a Method to Characterize Porous Fuel Cell Electrodes. Electrochim Acta 29(5):607-610

102. Mei BA, Lau J, Lin T, Tolbert SH, Dunn BS, Pilon L (2018) Physical Interpretations of Electrochemical Impedance Spectroscopy of Redox Active Electrodes for Electrical Energy Storage. J Phys Chem C 122(43):24499-24511

103. Holze R, Wu YP (2014) Intrinsically conducting polymers in electrochemical energy technology: Trends and progress. Electrochim Acta 122:93-107

104. Bandeira MCE, Holze R (2006) Impedance measurements at thin polyaniline films - the influence of film morphology. Microchim Acta 156(1-2):125-131

105. Jović VD, Jović BM (2003) EIS and differential capacitance measurements onto single crystal faces in different solutions: Part I $\mathrm{Ag}(111)$ in $0.01 \mathrm{M} \mathrm{NaCl}$. J Electroanal Chem 541:1-11

106. Holze R, Vielstich W (1984) The kinetics of oxygen reduction at porous Teflon-bonded Fuel cell electrodes. J Electrochem Soc 131(10):2298-2303

Publisher's note Springer Nature remains neutral with regard to jurisdictional claims in published maps and institutional affiliations. 